\title{
BMJ Open Partnering with consumers to develop and evaluate a Vietnamese Dementia Talking-Book to support low health literacy: a qualitative study incorporating codesign and participatory action research
}

\author{
Dianne Goeman, ${ }^{1} \mathrm{~J}$ Michael, ${ }^{1} \mathrm{~J}$ King, ${ }^{1}$ Huy Luu, ${ }^{2}$ Claire Emmanuel, ${ }^{3} \mathrm{~S} \mathrm{Koch}^{1}$
}

To cite: Goeman D, Michael J, King J, et al. Partnering with consumers to develop and evaluate a Vietnamese Dementia Talking-Book to support low health literacy: a qualitative study incorporating codesign and participatory action research. BMJ Open 2016;6: e011451. doi:10.1136/ bmjopen-2016-011451

- Prepublication history for this paper is available online. To view these files please visit the journal online (http://dx.doi.org/10.1136/ bmjopen-2016-011451).

Received 8 February 2016 Revised 28 June 2016 Accepted 18 August 2016

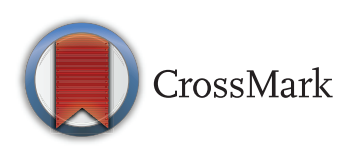

${ }^{1}$ RDNS Institute, Royal District Nursing Service Ltd, StKilda, Victoria, Australia ${ }^{2}$ Australian Vietnamese Women's Association, Richmond, Victoria, Australia ${ }^{3}$ Alzheimer's Australia Victoria, Parkville, Victoria, Australia

Correspondence to Dr Dianne Goeman; dgoeman@rdns.com.au

\section{ABSTRACT}

Objective: The aim of the Vietnamese Dementia talking-book was to address low health literacy in older people of Vietnamese background living with dementia through the provision of an online resource to help individuals, their families and carers better understand and manage this condition and provide information about available dementia services.

Design: This qualitative study used codesign and participatory action research to develop and refine the talking-book in consultation with expert stakeholders, a consumer advocacy group and the Vietnamese community to assess its utility and ensure cultural and linguistic appropriateness and relevance.

Participants: 59 members of the Vietnamese community, 11 stakeholders from community health services and ethnic agencies, consumer advocacy groups and the research team participated in the codesign and refinement of the talking-book. 22 members of the Vietnamese community appraised the final product.

Setting: Vietnamese community planned activity groups in the Western, Northern and Southern suburbs of Melbourne, Australia.

Results: Our codesign study outlines the process required to develop a Vietnamese Dementia TalkingBook resource partnering with consumers and expert stakeholders to identify consumer need, selection of the content and appropriate language level, construction of the book, measuring acceptability of the talking-book, modification based on feedback and production and dissemination. Feedback on the final version of the talking-book revealed widespread consensus that the book enhanced the knowledge of members of the Vietnamese community in regard to understanding dementia and navigation and accessing of available services.

Conclusions: This free internationally available online Vietnamese Dementia Talking-Book facilitates improved dementia-related health literacy in the Vietnamese community. The book also serves as a tool to facilitate the provision of care to Vietnamese people living with

\section{Strengths and limitations of this study}

- Codesign and participatory action research principles ensured that the talking-book was userfriendly, relevant and culturally appropriate.

- This is the first online resource to provide members of the Vietnamese community with greater access to information about living with memory loss. Additionally, we have created a free nationally and internationally available online tool for Vietnamese people with dementia, their carers, family members and health professionals.

- The easy to access online Vietnamese Dementia Talking-Book provides an opportunity to build a positive professional relationship that will develop a culturally safe environment for the client, their family and carers. This increase in understanding of personal circumstances and needs enables the introduction and tailoring of services or care plans that may help address any concerns.

- Older migrants are less likely to use online information and communication technology; however, this barrier can be overcome through arranging for the hard copy bi-lingual versions of the content of the Vietnamese Dementia Talking-Book to be made available in local municipal libraries with high Vietnamese populations.

memory loss by assisting health professional staff to develop relationships with Vietnamese clients, their families and carers in a culturally appropriate manner.

\section{INTRODUCTION}

Older people from culturally and linguistically diverse (CALD) backgrounds are at higher risk of experiencing a health crisis. ${ }^{12}$ Diagnosis of dementia in CALD communities 
occurs mainly in the later stages of the disease, and contact with health professionals and access to dementia services usually happens at crisis point. ${ }^{2-4}$ Although language is a primary barrier ${ }^{5}$ issues affecting seeking assistance earlier include having little knowledge about the symptoms and care of people with dementia, where to seek help and stigma. ${ }^{6}$ Factors affecting the uptake of dementia support services include lack of English, social isolation and access to culturally specific information and/or care. ${ }^{5}$

The Australian Vietnamese community is very diverse. To provide person-centred care to people of Vietnamese background, we need to understand the range of diversity characteristics that may be affecting on an individual to participate in their care. ${ }^{7}$ After the war in Vietnam in 1975, many Vietnamese people fled their home country and sought refugee status in Australia. The migration of Vietnamese people to Australia again dramatically increased in the 1990s with the implementation of the Vietnamese Family Migration Programme. In 2015, the Australian Bureau of Statistics reported 223180 (1.0\%) of the Australian population were Vietnamese-born. ${ }^{8}$ This represents the fifth largest migrant community in Australia. ${ }^{8}$ Thirty-eight per cent (84 320) of this population were above 50 years of age $e^{8}$ and $56 \%$ did not speak English well or not at all and due to living in a country at war often had no formal schooling in their own language. $^{9}$

Health literacy refers to the characteristics and social resources needed for people to access, understand and use information to make decisions about health. ${ }^{10}{ }^{11}$ It also includes health professionals capacity to communicate and affect the way people access, understand and appraise health-related information and services. ${ }^{11-14}$ New technologies have changed the way health information is disseminated by facilitating the promotion of health communication and self-management, the exchange of information and continuity of care beyond the face-to-face visit ${ }^{15}$ leading to an increasing responsibility on individuals to acquire and use information to manage their health. Subsequently, there has been an increase in the number of new technologies; however, little research has assessed how individuals with limited health literacy interact with these new technologies. ${ }^{16}$ To address the low literacy in older people of Vietnamese background living with cognitive impairment and provide an intergenerational tool that could be accessed through the internet, we developed an online Vietnamese Dementia 'talking-book' that covered aspects of dementia using simple information sheets and easy-to-understand, non-technical terminology. A 'talking-book' is a bi-lingual, multiple-media tool that can be viewed on a computer and accessed online. The talking-book can be used by an individual and/or their carer and families and as a teaching and learning resource to support health professional staff to provide health and care management education to Vietnamese clients. There is a choice of reading the information on-screen or listening to it. Listening to the information especially benefits older Vietnamese people with reading and literacy difficulties. This paper reports on the development of the 'talking-book' tool and its acceptability to the Vietnamese community.

\section{METHODS \\ Design}

The theoretical basis of the development of the talkingbook followed a codesign ${ }^{17}$ Participatory Action Research (PAR) methodology to select content and language, refine content and to evaluate the acceptability and utility of the Vietnamese Dementia talking-book. ${ }^{18}$ PAR is based on an iterative process that provides opportunity for communities to contribute to the research process by assisting researchers to gain an understanding of their lived experience and identifying and addressing the issues they face. ${ }^{18}$ The talking-book was developed using existing help sheets developed by Alzheimer's Australia Vic (AAV). An appraisal of the content was undertaken in collaboration with expert stakeholders, AAV and the Australian Vietnamese Women's Association (AVWA). After translation the content of the talking-book was again presented to the advisory group and to Vietnamese community members to ensure that it was culturally appropriate and met the needs of the Vietnamese community.

RDNS Translation Standards guided the process on the cultural and linguistic appropriateness of the content of the talking-book. ${ }^{19}$ The 10 components of the standards include:

- Develop the English text and/or text in consultation with the target community;

- Undertake a cultural and linguistic assessment of the English text prior to translation;

- Undertake a subject matter assessment of the English text as appropriate;

- Organise for the English text to be translated by a professional translator;

- Undertake a cultural and linguistic assessment of the translation (community consultation);

- Organise for the translation to be proofread by a professional translator;

- Include the title of the text in English on the translation;

- Include the name of the target language in English, on the English text and translation;

- Disseminate the translation in bilingual format (English and Vietnamese);

- Monitor, evaluate and update the English text and the translation as part of an ongoing review programme.

\section{Study setting}

The study was conducted in Western, Northern and Southern suburbs of Melbourne, Victoria, Australia. We consulted with members of the AVWA and Springvale 
Indochinese Mutual Assistance Association (SICMAA) Vietnamese seniors groups from both of these areas.

\section{Participants}

A convenience sample of people who originated from Northern, Central and Southern areas of Vietnam and stakeholders from different sectors (Four Vietnamese Community Groups, a Dementia Consumer Advocacy Group and Home Nursing Service provider staff) participated in providing insight into understanding issues faced by Vietnamese people experiencing memory problems, their literacy levels, cultural beliefs and any stigma associated with dementia in the development phase of the talking-book. Members of the research team approached potential participants using community networks, telephone and face-to-face contact. Participant groups were again involved in the evaluation phase of the final product.

\section{Data collection}

There were two main phases involved in the development of the talking-book. Selection and assessment of the English content and grade reading level prior to translation and production and then an evaluation of the finished product. Community consultation using focus groups to gain feedback on the content of the talking-book occurred in phase I. In phase II interviews and focus groups were used to evaluate the acceptability and utility of the final product. A semistructured interview guide was used to explore participants' experience of using the talking-book; whether it had assisted them; how the information was presented, how easy or difficult was it to use/access, if the information on dementia was useful and suggested changes.

\section{Phase I}

The purpose of phase I was to consult with the Vietnamese community in regard to the language and cultural appropriateness of the content selected for inclusion in the dementia talking-book. Focus groups were undertaken with two community groups to generate feedback on what aspects of the book needed modification. Interpreters were used to facilitate communication and two note takers, one English and one Vietnamese, recorded all feedback from the group on specifically designed information sheets.

\section{Phase II}

The purpose of phase II was to evaluate the acceptability and utility of the final version of the talking-book. An interview guide was used to promote discussion on the talking-book in regard to: language, content and structure, experience with using the book, ease of access and if it led to an increase in knowledge. Interviews or focus groups were undertaken with Vietnamese community members to explore their experience of using the talking-book and what aspects could be improved. Interpreters were used to facilitate communication.
Participants were selected from client records of a large home nursing organisation and from a large Vietnamese community activity group. Interviews and focus groups lasted between 30 and $60 \mathrm{~min}$.

\section{Data analysis}

Interviews were audio-recorded, transcribed, checked for accuracy and then imported into the NVivo10 qualitative software package(NVIVO10 Qualitative Software, Solutions and Research, Doncaster, Victoria, Australia.) to aid thematic analysis. ${ }^{20}$ Coding of the data started with descriptive and topic codes, followed by identification of themes. The team met to ensure that there was agreement on the themes and all interpretations of the data were included. Interviews continued until data saturation was reached, that is, the point when no new themes are identified.

A descriptive analysis of participant demographics was undertaken using SPSS V.21 (IBM).

\section{Ethics approval}

Ethics approval to conduct the study was obtained from the RDNS Human Research Ethics Committee (Project 155). Written informed consent was obtained from all study participants. Interpreters where used to facilitate this process.

\section{RESULTS}

\section{Participants-phase I: development of the Vietnamese} Dementia Talking-Book

The research team, members of the AAV the peak consumer advocacy body for dementia education advisory group and an expert Vietnamese linguist formed a working group to facilitate the selection of appropriate English content and its simplification to aid the translation of the final content into Vietnamese. Pre-translation assessments were undertaken by the AAV Learning and Development Advisory Group, the AAV cultural advisor and Vietnamese service providers to ensure that the information was culturally appropriate, non-offensive and covered topics that were important and relevant to the Vietnamese community in Australia and that the information was current and contact information accurate. Results from these assessments were that the standard of the information was very high and the working group was commended on having such a great outcome.

Overall the written material embraces AAVs philosophy and uses correct terminology that is, follows the person centred approach and encourages respect and dignity. (Learning and Development Advisory Group-AAV)

The content was then translated into Vietnamese by a professional translation company and presented to the Vietnamese community for consultation. The community consultations took place in December 2014 and January 2015. Fifty-nine participants $(54$ females and 5 males) ranging in age from 65 to 94 years with an 
average age of 74 years participated in two community consultation sessions to provide feedback on the proposed content and language of the talking-book to ensure its acceptability. Twenty-three of the participants had arrived in Australia in the 1970s or 1980s with the remaining 36 having arrived in the 1990s. Eleven of the 59 participants had no schooling in Vietnamese and 30 had no schooling in the English language (see table 1).

Feedback from the two community consultations with the AVWA Vietnamese community was very positive. An example of the comments from the group included:

The terminology you have used is the best way to explain Dementia.

(Focus group participant 1)

I am so happy it is in Vietnamese and English, it means 1 can share the information with my family who do not understand Vietnamese.

(Focus group participant 20)

However, it was noted that some of the Vietnamese language used had a negative connotation attached to it and other participants noted grammatical errors in the Vietnamese. This information was identified, corrected and sent back to the translator for editing.

Once the suggested amendments were undertaken AVWA sourced a suitable narrator for the talking-book, a male employee of AVWA whose voice and accent was considered to be easily understood by all members of the Vietnamese community. A production company with experience in the development of the talking-book platform was employed to orchestrate the recording of the information sheets in the Vietnamese language and to construct the talking-book. Each page was recorded separately and electronically filed and catalogued to ensure the information would correspond to the correct information sheet.

\begin{tabular}{lc}
\multicolumn{2}{l}{ Table 1 Focus group participant demographics } \\
\hline Participants & $\mathbf{n = 5 9}$ \\
\hline Age & $75.6 \pm 8.6$ \\
$\quad$ (Mean and SD) & \\
Gender & $54(91.5 \%)$ \\
$\quad$ Female & $5(8.5 \%)$ \\
Male & \\
Arrival in Australia & $23(9 \%)$ \\
1970-1980s & $36(61.0 \%)$ \\
1990s & \\
Education & $11(19 \%)$ \\
$\quad$ No formal education Vietnamese & $24(41 \%)$ \\
Education in Vietnamese $<7$ years & $24(41 \%$ \\
Education in Vietnamese $>7$ years & $30(51 \%)$ \\
No education in English language & $21(36 \%)$ \\
Education in English $<2$ years & $8(13 \%)$ \\
\hline Education in English $>2-6$ years &
\end{tabular}

During the recording process errors were revealed in several of the information sheets and these were marked for correction. These errors were able to be corrected immediately in the English information and the translated versions corrected soon after. The voice recordings, narrator photo and all written information was then provided to the production company for construction into an electronic 'talking-book'. This process took 2 weeks. Once the electronic talking-book was received then the RDNS Information Technology Department organised the uploading of the program in readiness for the CEOs of AAV, AVWA and the Director of the RDNS Institute launching of the Vietnamese Talking-Book at Vietnamese Community Activity group on 24 April 2015.

\section{Talking-book production}

The overall process in the development and the evaluation of the Vietnamese Dementia Talking-Book required the following steps: partnering with consumers and stakeholders, identification of consumer information needs, development of a project working group, development of outcomes, drafting of the talking-book content and grade reading level in English, professional translation of content into Vietnamese and construction of the talking-book, assessing acceptability of the content of the information in the talking-book, making modifications based on feedback, production and dissemination, evaluation of the talking-book and ongoing maintenance (see figure 1).

\section{Participants-phase II: evaluation of the acceptability and} utility of the Vietnamese dementia talking-book

Twenty-two Vietnamese people ( 17 women and 5 men) participated in either a focus group or an individual interview to evaluate the final version of the talkingbook. The average age of these participants was 61 years (range between 43 and 78 years). Approximately 50\% of this group had arrived in Australia during 1970s and 1980s with the remaining having arrived between 1990 and 2013 (see table 2).

Feedback from the interviews with these Vietnamese community members demonstrated that participants were very satisfied with the content, and the format and structure of the talking-book and its cultural appropriateness. Participants also reported an increase in knowledge about dementia, how to assist/interact with people with dementia and where they could access information and services to assist people who are experiencing memory problems. There were mixed responses as to whether participants preferred to view the book online via the internet, access it using a USB, or actually print it off and read it as a hard copy (see table 3 ).

Although talking-book is available free on the RDNS, AAV and AVWA websites, several participants asked that the talking-book is made available through local municipal libraries. To facilitate this, an ISBN number has been obtained and hard copies of the book have been printed. Contact with local libraries in the South 


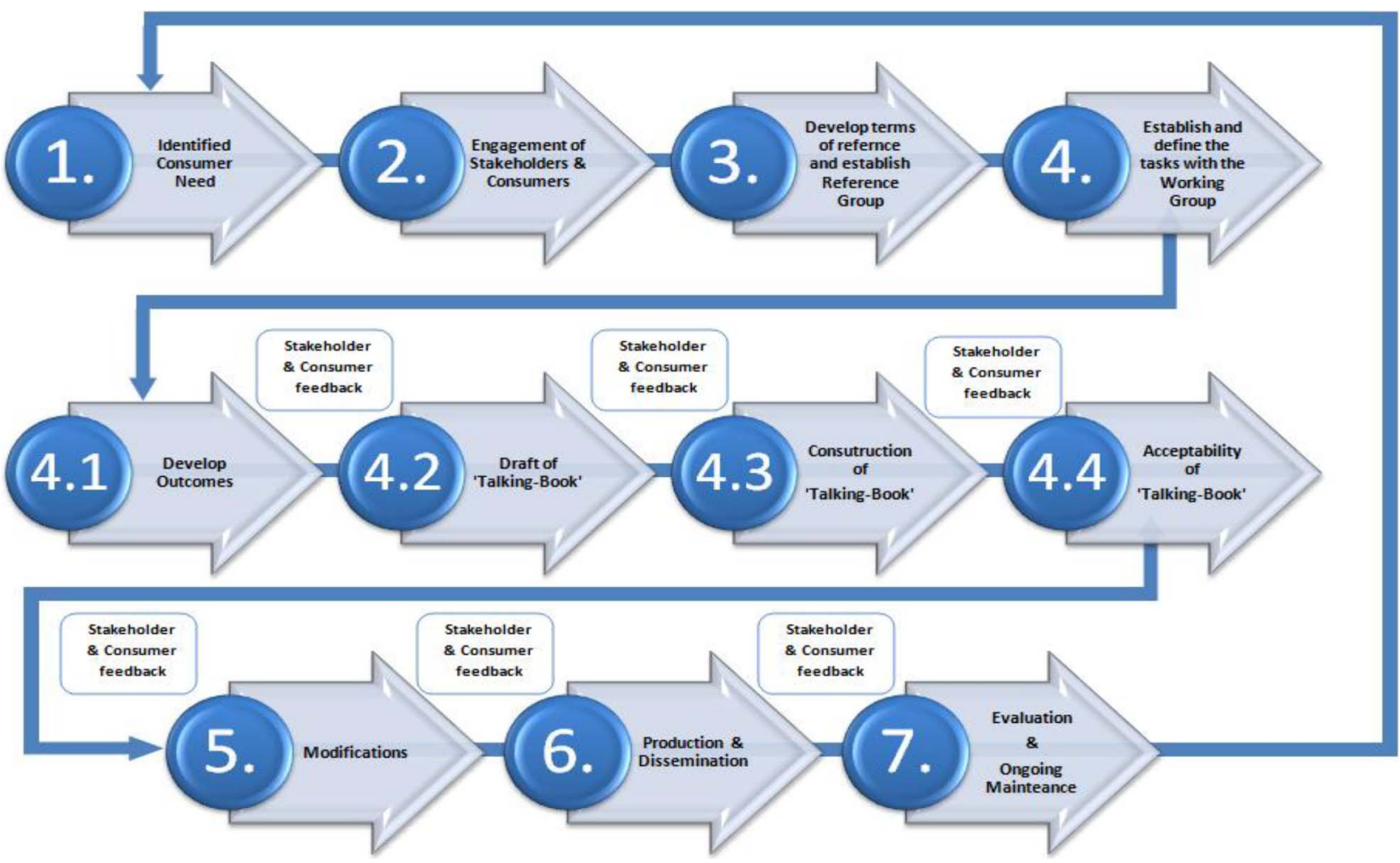

Figure 1 Steps in the development of a bi-lingual talking-book.

\begin{tabular}{|c|c|}
\hline Participants & $\mathrm{n}=22$ \\
\hline \multicolumn{2}{|l|}{ Age } \\
\hline (Mean and SD) & $61 \pm 10.9$ \\
\hline \multicolumn{2}{|l|}{ Gender } \\
\hline Female & $17(77.0 \%)$ \\
\hline Male & $5(23.0 \%)$ \\
\hline \multicolumn{2}{|l|}{ Arrival in Australia } \\
\hline 1970-1980s & $11(50.0 \%)$ \\
\hline Post 1990s & $10(45.0 \%)$ \\
\hline Unknown & $1(5.0 \%)$ \\
\hline \multicolumn{2}{|l|}{ Education } \\
\hline No formal education Vietnamese/English & $2(9.0 \%)$ \\
\hline Education in Vietnamese/English $<7$ years & $3(13.5 \%)$ \\
\hline Education in Vietnamese/English $>7$ years & $17(77.5 \%)$ \\
\hline
\end{tabular}

Eastern, Northern and Western regions of Melbourne, areas with a high Vietnamese population, to facilitate the distribution of the book is in progress.

\section{DISCUSSION}

The Vietnamese Dementia Talking-Book has been well received by the Vietnamese community. The book has enhanced the knowledge of members of the Vietnamese community who participated in focus groups in regard to understanding of dementia and navigating and accessing available services, thus enabling making decisions about their care. It also serves as a tool that is able to facilitate the provision of care to Vietnamese people living with memory loss by assisting health professional staff to develop relationships with Vietnamese clients, their families and carers in a culturally appropriate manner.

In a recent report by the $\mathrm{WHO}$, it was suggested that low health literacy 'significantly drain(s) human and financial resources in the health system'. ${ }^{21}$ For example, it is estimated that people with low individual health literacy are between one-and-a-half and three times more like to experience adverse outcomes, higher rates of hospitalisation and emergency care. ${ }^{22}$

While there are commonalities across older Australians, many older Australians from culturally and linguistically diverse backgrounds (CALD) face circumstances that differ and that may affect not only their ageing experience due to different cultural beliefs, stigma and understandings about chronic illnesses but also their access to and use of aged care services. ${ }^{7} 2324$ With a rapidly ageing Australian population and a strong preference for older Australian's to remain living in their own homes for, as long as possible, the development of strong systems of support for all community members are vital. ${ }^{23}$ The aim of our project, therefore, was to provide a tool to address low dementia literacy in older Vietnamese people living with cognitive impairment, by developing an online 'talking-book' to help individuals, and their families and carers better understand and manage their condition. The talking-book 
Table 3 Key themes and illustrative quotes

\begin{tabular}{ll}
\hline Themes & Findings \\
\hline Dementia knowledge & $\begin{array}{l}\text { The talking-book increases your knowledge about dementia and how } \\
\text { to assist people with dementia }\end{array}$
\end{tabular}

Illustrative quotes

to assist people with dementia

Accessing dementia services/information

Appropriateness and
The talking-book provided information on where to access information and services to assist people experiencing memory problems

The narration of the book was found to be clear, easy to follow and the language used.

Most participants found the book to be culturally appropriate; however, two participants commented on the level of the language and acceptability of the language being relevant to the region in Vietnam that one originates from

'It helps improve understanding of these people and how to interact with them and how to help them' (Participant 3: male)

'I think it's very good because if I know there are people with dementia and we don't know how to help them or we have to live with them, when don't know how to deal with this so this one is really good' (Focus Group 2: female)

'So it's really very useful because everyone can understand about dementia. I find the information today is so helpful for me especially for my family because my mother in law has started having the problems, the symptoms of dementia so it's really good for me to understand that she's having to go through the symptoms.' (Focus Group 2: female) 'this direct you to where you can get help. That mean the dementia hotline. You can read and you can follow the instructions, you can get help from your medical professional. You can see your family doctor, GP, or you can call up the interpreter service to help you if you have trouble with English' (Participant 1: male).

'The voice is very clear and he pronounces the words clearly, so it's good. It's a good choice of the person reading it' (Focus Group 3: male) 'So a good thing about it is the pace of reading, it's slow. It's easy to understand' (Focus Group 2:female). (Focus Group 2:

'I think the talking aspect is for the people who, with the English barrier, and some people, because in our country, lots of old people they don't have good education. Even in Vietnamese, they have problem with understand all the wording so lucky I finished Year 11. That means my Vietnamese is quite good. Other people only finish Year 7, Year 8 and because of the war, because of the poor condition of the country or where they grow up they have to work to make a living and to provide for the family'. (Participant 1: male)

'...this is a very good one. People who don't understand in writing, they can understand in listen' (Participant 1: male).

'When you use the word of having deteriorating mind, then it's a little bit difficult for Vietnamese to accept. If you say like, the memory, there is loss of memory or decreased memory or something, its probably easier to accept or understand...to say it shows the decrease in intellect, that makes it a little bit too academic'. (Participant 3: male)

'Cuốc bộ is speaking for a joke or things like that like joking...đi bộ is easier to understand....and Cuôc bô used for the person who lives in the north not for the south and the centre of Vietnam' (Focus Group 1: female) 


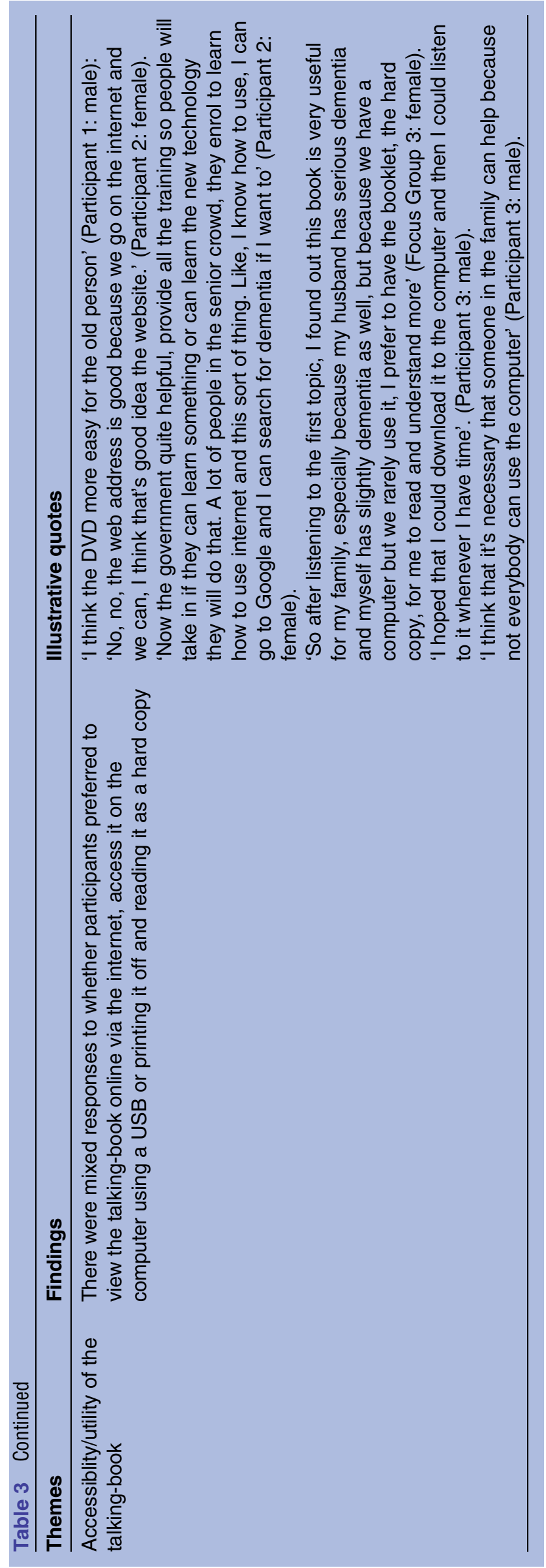

addresses the two components of health literacy as described by the Australian Commission on safety and quality in healthcare individual health literacy and the health literacy environment. ${ }^{25}$

\section{Strengths and weaknesses}

While talking-books on diabetes in several languages have previously been developed by our group and the relevant ethnic communities, these earlier talking-books were not part of a research study that documented and described the processes involved in the production of such a tool or an evaluation of the acceptability of the final product. The Vietnamese Dementia Talking-Book used codesign and participatory action research principles to develop and appraise the final book to ensure that it was user-friendly, relevant and culturally appropriate. ${ }^{1726}$ This innovative tool is the first online resource to provide members of the Vietnamese community with greater access to information about living with memory loss, additionally a free nationally and internationally available online tool for Vietnamese people with dementia, their carers and family members and health professionals delivering care to this group has been created. Within the community, those delivering care to Vietnamese people in the home setting are able to access the Vietnamese Dementia Talking-Book online. In the clients home there is opportunity to build a positive professional relationship that will develop a culturally safe environment for the client, their family and carers to disclose further information to the nurse in order so that we can better understand their circumstances and needs ${ }^{7}$ and adjust and introduce services or care plans that may help address their concerns.

Older migrants are less likely to use online information and communication technology; ${ }^{11} 2627$ however, this barrier can be overcome through accessing the hard copy bi-lingual versions of the content of the Vietnamese Dementia Talking-Book that is being made available in local municipal libraries with high Vietnamese populations and Alzheimer's Australia libraries. AVWA have also stated that as the book is so effective and can be accessed online and off-line by all generations of Australian Vietnamese people that they will take action to introduce it to the Vietnamese community across Victoria.

\section{CONCLUSION}

This freely internationally available online Vietnamese Dementia Talking-Book facilitates improved dementia-related health literacy in the Vietnamese community. The book also serves as a tool to facilitate the provision of care to Vietnamese people living with memory loss by assisting health professional staff to develop relationships with Vietnamese clients, their families and carers in a culturally appropriate manner. We recommend that further research using a randomised controlled trial design be undertaken to evaluate the full impact of the Vietnamese talking-book on health literacy outcomes. 
Acknowledgements The authors acknowledge the contribution of the all members of the project reference group and that Home and Community Care (HACC) services provided by RDNS are jointly funded by the Victoria and Australian Governments. They also acknowledge the Vietnamese community members who participated in the interviews and focus groups and the contributions of Lawrence Walsh and Rosemarie Draper during the Vietnamese community focus group sessions.

Contributors JM, SK and DG conceived and initiated the study. JK, SK, DG and $\mathrm{JM}$ developed the talking-book together with the project working group members from AVWA (HL) and AAV (CE). DG and JK undertook the data collection, DG and JK undertook the data analysis and the final drafting of the article and revised it for critical content. All authors contributed to and approved the final version of the paper and accept accountability for all aspects of the work

Funding The project was funded by Samuel Nissen Charitable Foundation, managed by Perpetual.

Competing interests None declared.

Patient consent Obtained

Ethics approval RDNS Human Research Ethics Committee.

Provenance and peer review Not commissioned; externally peer reviewed.

Data sharing statement No additional data are available.

Open Access This is an Open Access article distributed in accordance with the Creative Commons Attribution Non Commercial (CC BY-NC 4.0) license, which permits others to distribute, remix, adapt, build upon this work noncommercially, and license their derivative works on different terms, provided the original work is properly cited and the use is non-commercial. See: http:// creativecommons.org/licenses/by-nc/4.0/

\section{REFERENCES}

1. Alzheimers Australia Vic Report, 2008: Perceptions of dementia in ethnic communities. https://fightdementia.org.au/sites/default/files/ 20101201-Nat-CALD-Perceptions-of-dementia-in-ethniccommunities-Oct08.pdf

2. Ethnic Communities Council of Victoria. An investment not an expense: enhancing health literacy in culturally and linguistically diverse communities. Policy Paper. 2012.

3. Lee SM, Lin X, Haralambous B, et al. Factors impacting on early detection of dementia in older people of Asian background in primary healthcare. Asia-Pacific Psychiatry 2011;3:120-7.

4. Xiao LD, De Bellis A, Habel L, et al. The experiences of culturally and linguistically diverse family caregivers in utilising dementia services in Australia. BMC Health Serv Res 2013;13:427.

5. Australian Institute of Health and Welfare. Dementia in Australia. Cat. No. AGE 70. Canberra: AlHW, 2012.

6. Liu D, Hinton L, Tran C, et al. Reexamining the relationships among dementia, stigma, and aging in immigrant Chinese and Vietnamese family caregivers. J Cross Cult Gerontol 2008;23:283-99.

7. Michael J. Diversity conceptual model for aged care: person-centred, difference-oriented and connective with a focus on benefit, disadvantage and equity. Australas J Ageing 2016;35:210-15.

8. Australian Bureau of Statistics. 3412.0-Migration, Australia, 201314. Canberra, ACT: Australian Bureau of Statistics, 2015. (updated
30 March 2015; cited 02 June 2015). http://www.abs.gov.au/ AUSSTATS/abs@.nsf/Lookup/3412.0Main+Features12013-14? OpenDocument

9. Economic Analysis Department, Department of Immigration and Border Protection. County Profile Vietnam. Canberra, Australia: Australian Government, 201310pg.

10. Keleher $\mathrm{H}$, Hagger V. Health literacy in primary health care. Aust J Primary Health 2007;13:24-30.

11. Michael J, Aylen T, Petralia W. Italian diabetes information: the perceptions and suggestions of older Italians living in Melbourne. Aust Diabetes Educ 2015;18.

12. Helitzer D, Hollis C, Sanders M, et al. Addressing the 'Other' Health Literacy competencies-knowledge, dispositions and Oral/Aural communication: development of TALKDOC, an intervention assessment tool. J Health Commun 2012;17(Suppl 3):160-75.

13. Naik $A D$, Street RL Jr, Castillo D. Health literacy and decision making styles for complex antithrombotic therapy among older multimorbid adults. Patient Educ Couns 2011;85:499-504.

14. Dodson S, Beachamp A, Batterham R, et al. Information Sheet 1: What is health literacy. In: OPHELIA Toolkit: a step by step guide for identifying and responding to health literacy needs within local communities. Part A:Introduction to health literacy. 2014. http://www. ophelia.net.au.In

15. Greenhalgh T, Hinder S, Stramer K, et al. Adoption, non-adoption and abandonment of a personal electronic health record. Case study of Healthspace. BMJ 2010;341:c5814.

16. Yip M. A health literacy model for limited English speaking populations: sources context, process and outcomes. Contemp Nurse 2012;40:160-8.

17. Aitken J, Shackleton D. 2014. Co-creation and co-design: applied research methods in healthcare service design. IN SAGE research methods cases. London, UK: Sage Publications Ltd, 2014.

18. Cornwall A, Jewkes $\mathrm{R}$. What is participatory research? Soc Sci Med 1995;41:1667-76.

19. Michael J, Aylen T, Ogrin R. Development of a Translation Standard to support the improvement of health literacy and provide consistent high-quality information. Aust Health Rev 2013;37:547-51.

20. Pope C, Ziebland S, Mays N. Qualitative research in health care: analysing qualitative data. BMJ 2000;320:114-16.

21. WHO. Health literacy: the solid facts. Copenhagen: WHO, 2013.

22. DeWalt D, Berkman N, Sheridan S, et al. Literacy and health outcomes: systematic review of the literature. J Gen Intern Med 2004;19:1228-39.

23. Federation of Ethnic Communities Council of Australia (FECCA). Multicultural access and equity: building a cohesive society through responsive services. FECCA. 2015.

24. Dandan L, Hinton L, Tran C, et al. Reexamining the relationships among dementia, stigma and aging in immigrant Chinese and Vietnamese family caregivers. J Cross Cult Gerontol 2008;23:283-99.

25. Australian Commission on Safety and Quality in Health Care. Consumers, the health system and health literacy: taking action to improve safety and quality. Consultation paper. Sydney: ACSQH, June 2013.

26. Goodall K, Ward P, Newman L. Use of information and communication technology to provide health information: what do older migrants know, and what do they need to know? Qual Prim Care 2010;18:27-32.

27. O'Mara B. Aged care, cultural and linguistic diversity and IT in Australia: a critical perspective. Int J Migr Health Soc Care 2014;10:73-87. 